\title{
Wear study of $\mathrm{Mg-SiCp}$ reinforcement aluminium metal matrix composite
}

\author{
M.A. Maleque ${ }^{1 *}$, M. Radhi ${ }^{1}$ and M.M. Rahman ${ }^{2}$ \\ ${ }^{1}$ Department of Manufacturing \& Materials Engineering, International Islamic \\ University Malaysia, \\ 53100 Kuala Lumpur, Malaysia \\ *Email:maleque@iium.edu.my \\ Tel: +6 0361965785; Fax: +6094246222 \\ ${ }^{2}$ Automotive Engineering Centre, Universiti Malaysia Pahang, \\ 26600 Pekan, Pahang, Malaysia
}

\begin{abstract}
Lightweight aluminium metal matrix composite materials hold potential requisite for modern tribological applications due to its inherent and better wear resistant properties over monolithic metallic materials. This study emphasised on the development of $\mathrm{Al}$ based metal matrix composite with $\mathrm{SiCp}$ as a reinforcement and magnesium $(\mathrm{Mg})$ as a wetting agent using hybrid stir casting process. The study further analysed the effects of different size variations of silicon carbide particles such as the coarse particle size, fine particle size, intermediate particle size and mixed particle size in the fabrication of the composites on the hardness and wear properties. The pin-on-disc test was also done at room temperature in a dry sliding wear condition. It was observed that the mixed particle size $\mathrm{SiCp}$ in composite exhibited superior hardness with the value of 98.2 compared to other particle sizes of SiCp. This is due to the fact that mixed particle size supports a greater fraction of applied load while the fine and intermediate particle sizes sustain the hardening due to dislocation. The multiple particle size reinforced composite exhibits better performance than the single particle size in terms of wear resistance as the wear rate was the lowest with the value of $0.99 \times 10^{-5}$. It can be concluded that the Mg addition in the composite showed better and tailored properties with a mixed particle size of SiCp of aluminium metal matrix composite.
\end{abstract}

Keywords: Metal matrix composite, hybrid stir casting, wear, dry sliding, pin-on-disc

\section{INTRODUCTION}

Metal matrix composites possess enhanced properties in strength, stiffness and density. As for the cost effectiveness, particle reinforced composites are more attractive than fibre reinforcements [1-3]. Aluminium alloys are very soft and have limited properties in terms of hardness and wear resistance, however, these properties can be relatively made highly resistant by introducing predominantly hard but brittle particles such as $\mathrm{SiC}, \mathrm{Al}_{2} \mathrm{O}_{3}$, and $\mathrm{B}_{4} \mathrm{C}$ [4]. Recent researches [5-9] have shown that aluminium matrix composite (AMC) possesses desired potential properties such as high specific strength and stiffness, required wear resistance to withstand abrasive properties compared to monolithic materials which are demanded by automotive and aerospace industries for the tribological application. Other researchers [10-14] showed that silicon carbide ( $\mathrm{SiC})$ is ideal reinforcement candidate for several matrix materials, including aluminium because of its significant 
ability to enhance the strength, modulus, thermal stability, and abrasive wear resistance of the matrix materials.

Generally, the wear and mechanical properties of composites are influenced by the particle size variations and volume or weight fraction. Mishra et al. [9] investigated the influence of applied load, sliding speed and sliding distance on the wear rate and coefficient of friction. Huang et al. [15] reported that the wear resistance of AMCs with $3 \mu \mathrm{m} \mathrm{SiC}$ particles is considerably lower compared to $20 \mu \mathrm{m} \mathrm{SiC} \mathrm{particles.} \mathrm{This}$ phenomenon is attributed to the tendency of finer reinforced particles to be easily gouged out and machined away by abrasive particles. Bindumadhavan et al. [16] studied the tribological behaviour of a low volume fraction dual particle size (DPS) containing both small $(47 \mu \mathrm{m})$ and large $(120 \mu \mathrm{m}) \mathrm{SiC}$ particles reinforced composite and compared with a single particle size (SPS) of $(47 \mu \mathrm{m})$ reinforced composite. They found that the DPS composite exhibited better wear resistance and impact energy compared to the same volume fraction of SPS composite. Ding et al. [12] investigated the wear and friction coefficient of a single particle size $(22.8 \mu \mathrm{m}) \mathrm{SiCp} / \mathrm{Al}$ alloy composite for the automotive brake rotor. The study showed that the composite possesses the potential to attain better properties when compared to the commercial cast iron rotor material as specified by TL110 standard with further extensive studies. From previous studies, limited or no attempt has been made to study the role of different size variations of silicon carbide particles such as coarse particle size (CPS), fine particle size (FPS), intermediate particle size (IPS) and mixed particle size. Therefore, this present study aims to investigate the influence of different size variations of $\mathrm{SiC}$ and addition of $\mathrm{Mg}$ in $\mathrm{Al}$-alloy on the hardness and wear characteristics of a developed composite.

\section{EXPERIMENTAL DETAILS}

\section{Materials and Methods}

The matrix and reinforcement phase materials utilised for this study are Al 6061 alloy, silicon carbide particulate ( $\mathrm{SiCp}$ ) and magnesium in the ratio 90:9:1 respectively. The SiCp comprises three different particle sizes of average mean sizes; $15 \mu \mathrm{m}$ (fine), $40 \mu \mathrm{m}$ (intermediate) and $80 \mu \mathrm{m}$ (coarse). The composite was developed using the liquid metallurgy route through the bottom pouring stir casting technique. The SiCp was preheated to $900^{\circ} \mathrm{C}$ whereas the $\mathrm{Al} 6061$ alloy was superheated to a temperature of $750^{\circ} \mathrm{C}$. The previous study showed that $10 \% \mathrm{SiC}$ is the best reinforcement for aluminium matrix composite [7]; however, in this study $1 \% \mathrm{Mg}$ was added as a wetting agent, hence, SiC percentage was reduced to $9 \%$. The aluminium matrix composite (AMC) was prepared into four different constituent sizes with $9 \mathrm{wt} \%$ silicon carbide particulate ( $\mathrm{SiCp}$ ) and $1 \%$ $\mathrm{Mg}$ formulations as indicated in Table 1. The chemical composition of the $\mathrm{Al} 6061$ and properties of $\mathrm{SiC}$ can be found elsewhere [4].

Table 1 Formulation of AMCs with different size variations of SiCp.

\begin{tabular}{ccccc}
\hline $\begin{array}{c}\text { Formulation and } \\
\text { designation }\end{array}$ & $\begin{array}{c}\text { Aluminium } \\
(\%)\end{array}$ & $\begin{array}{c}\text { Silicon } \\
\text { Carbide }(\%)\end{array}$ & $\begin{array}{c}\text { Magnesium } \\
(\%)\end{array}$ & $\begin{array}{c}\text { Particle size with } \\
\text { abbreviation }\end{array}$ \\
\hline AMC I & 90 & 9 & 1 & Fine SiC; FPS \\
AMC II & 90 & 9 & 1 & $\begin{array}{c}\text { Intermediate SiC, } \\
\text { IPS }\end{array}$ \\
AMC III & 90 & 9 & 1 & Coarse SiC, CPS \\
AMC IV & 90 & 9 & 1 & Mixed SiC, MPS \\
\hline
\end{tabular}




\section{Composite Development}

Aluminium was prepared in a form of blocks, whereas silicon carbide and magnesium were prepared in a form of powders. Firstly, there was a preheating of the hybrid furnace for 30 minutes. Next, aluminium blocks were put inside the furnace and preheated for 30 minutes at $450^{\circ} \mathrm{C}$ and silicon carbide powder was also preheated at $900^{\circ} \mathrm{C}$ for 1 hour in the furnace in order to oxidise the surface. After that, the aluminium melted completely at $750^{\circ} \mathrm{C}$ since the melting point of aluminium is $660^{\circ} \mathrm{C}$ and the magnesium powder was added to the aluminium melt. Before that, the magnesium powder was wrapped using aluminium foil since magnesium is reactive and highly flammable. The mixture of melted aluminium and magnesium powder was stirred for a $\sim 30$ second and once the temperature of the preheating silicon carbide was reached, the heated silicon carbide was dropped to the mixture of aluminium in the hybrid furnace. Then the stirring process took place for another three minutes to allow the materials to be mixed and distributed uniformly. The stirring speed of the blade was $550 \mathrm{rpm}$, and the melted mixture started to flow into the mould which was prepared under the furnace. The mould was carried out from the vacuum chamber and allowed to cool to room temperature. Once the melted mixture solidified and cooled down, the mould was unscrewed to split and release the cast composite materials from the mould for sample preparation.

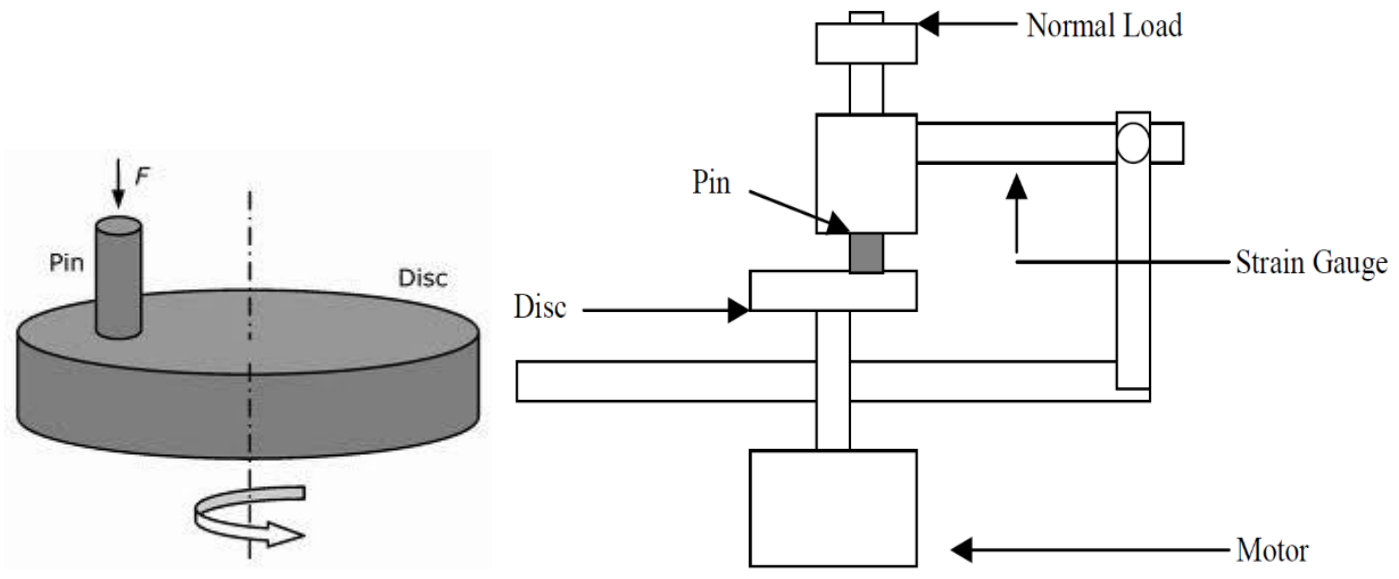

Figure 1. Schematic view of pin on the disc tribosystem for wear testing [17].

\section{Wear Testing}

The cast samples were milled to obtain the standard wear samples in a form of disc shape with a diameter of $41 \mathrm{~mm}$ and thickness of $9.5 \mathrm{~mm}$. Then, the edge of the disc specimens was drilled in order to create the holes. The purpose of making these holes is to be able to screw up using the pin on the disc type wear machine. Figure 1 shows the schematic view of the tribosystem utilised for this study. The test was conducted according to ASTM G4 standard procedure. The data was taken from the average of three test results. The wear test was conducted in order to study the effect of the particle size variation on AMC. The wear rate was analysed from the Eq. (1):

$$
\mathrm{W}_{\mathrm{r}}=\frac{\Delta \mathrm{w}}{2 \pi \mathrm{rnt}}
$$

where, $\mathrm{Wr}$ is the wear rate, $\Delta \mathrm{w}$ is weight loss, $\mathrm{n}$ is revolution per minute, $\mathrm{r}$ is the radius of AMC composite disc, $\mathrm{t}$ is time. 


\section{RESULTS AND DISCUSSION}

\section{Hardness Property}

The Rockwell hardness test was performed in accordance with ASTM E18 - 14a at room temperature. Based on the average results, AMC IV with MPS had the highest hardness value of $98 \mathrm{HRB}$ as shown in Figure 2. The maximum hardness was achieved as a result of the combined influence of the three sizes. The mixed particle size (MPS) influenced greatly on the hardness increment of the AMC. This is due to the fact that mixed particle size (MPS) supports a greater fraction of the applied load while the fine particle size (FPS) and intermediate particle size (IPS) sustain hardening due to dislocation [4]. Moreover, the fine particle sizes (FPS) possess a greater amount of particle-matrix interface which enhances more hardening due to dislocations. Also, IPS provides additional support for the resistance to deformation by bridging the inter-particle spacing gap for the CPS and FPS to improve the hardness of AMC IV.

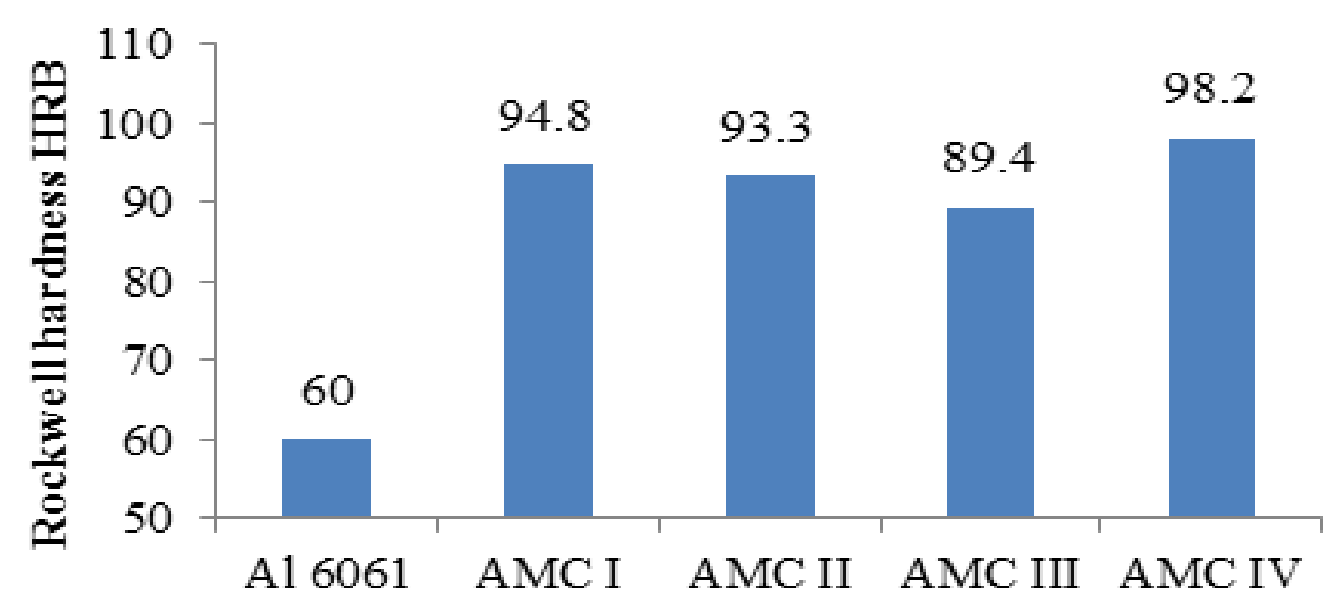

Aluminium and AMC

Figure 2 Hardness value for different AMC variations.

\section{Wear Analysis}

Table 2 depicts the wear rate of different AMCs with different formulations of particles size of SiCp such as AMC I, AMC II, AMC III and AMC IV. Figure 3 demonstrates the macroscopic image and micrograph of the worn surface under SEM. AMC IV exhibited higher wear resistance (as the wear rate value showed lowest in Table 2) compared to other AMCs with other size variations of $\mathrm{SiCp}$. This is the result of the load bearing capacity of the mixed particle size (MPS). The better interfacial bonding in the presence of $\mathrm{Mg}$ which exists between the matrix and MPS is achieved due to the large surface bonding which makes it difficult for the particle pull-out from the matrix. This strong bonding provides a shielding effect for the IPS and FPS which could improve properties such as toughness and strength.

In Figure 3, the SEM image of the worn surface of AMC IV (MPS-AMC) can be characterised by the localised narrow/shallow grooves and less fragmented particles. The smooth surface on the worn AMC III and AMC IV could be ascribed to the load bearing capacity demonstrated by the CPS providing multiple shielding for the matrix. A similar observation was found by others $[16,18]$. AMC IV exhibited high wear resistance when 
compared to other AMC variations. This is the result of the load bearing capacity of the coarse particle size. The high interfacial strength which exists between the matrix and MPS was achieved due to the large surface bonding which made it difficult for the particle pull-out from the matrix. The lowest in the wear rate was presented by the AMC IV (refer to Table 2) which consists of multiple size particles of silicon carbide with multiple shielding effects that enhance the load bearing properties of the composite thereby reduce the wear rate of the composite. From the image of the AMC IV sample (Figure 3), the worn surface was characterised by the localised shallow grooves and very fine scratches under SEM micrograph. This is due to the load bearing capacity of the particle mixture [7, 19]. It is noteworthy that MPS along with Mg element in AMC showed better performance in terms of hardness and wear resistance. Finally, it can be said that the current study reveals that the MPS-SiCp enhances the wear resistance and hardness properties as compared to FPS when mixed in a definite proportion.

Table 2. Wear rate of different AMCs with different formulations of particle size of $\mathrm{SiCp}$.

\begin{tabular}{lcccc}
\hline & AMC I & AMC II & AMC III & AMC IV \\
\hline Initial mass $(\mathrm{g})$ & 31.75 & 33.18 & 32.33 & 33.50 \\
Final mass $(\mathrm{g})$ & 31.51 & 32.99 & 32.18 & 33.37 \\
Density $\left(\mathrm{g} / \mathrm{cm}^{3}\right)$ & 2.06 & 2.14 & 2.14 & 2.15 \\
Radius $(\mathrm{cm})$ & 0.67 & 1.00 & 0.95 & 0.90 \\
Frequency of rotation $(\mathrm{rpm})$ & 107 & 107 & 107 & 107 \\
Time $(\mathrm{min})$ & 10 & 10 & 10 & 10 \\
Wear rate $\left(\mathrm{cm}^{3} / \mathrm{min}\right)$ & $2.59 \times 10^{-5}$ & $1.32 \times 10^{-5}$ & $1.09 \times 10^{-5}$ & $0.99 \times 10^{-5}$ \\
\hline
\end{tabular}

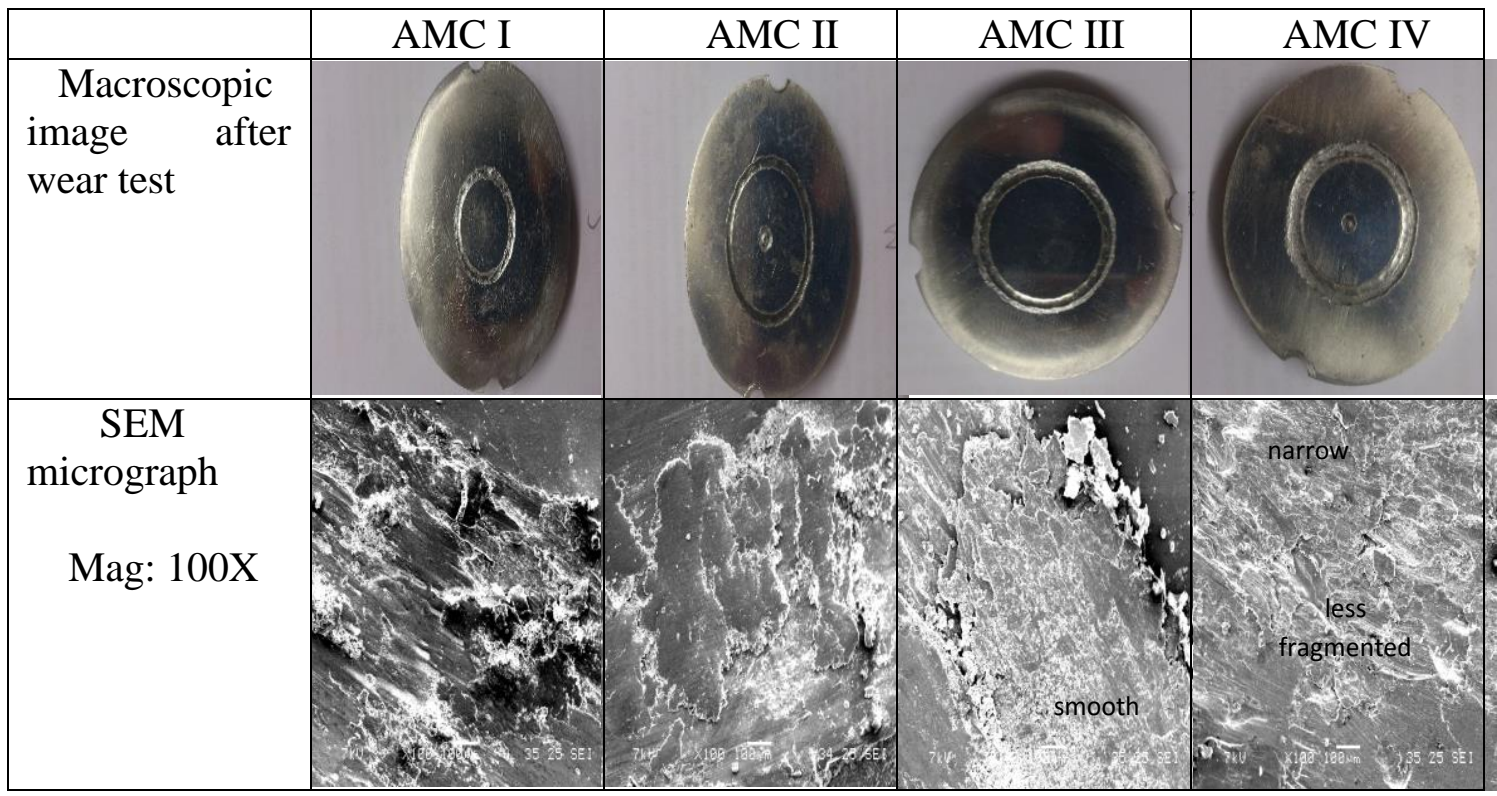

Figure 2. Macroscopic image (top) and SEM micrograph (bottom) of wear worn surface of $\mathrm{Mg}-\mathrm{SiCp}$ reinforcement aluminium matrix composites. 


\section{CONCLUSIONS}

In this paper, the $\mathrm{Mg}$-SiCp reinforcement aluminium metal matrix composite was developed successfully and the wear test was conducted using the pin-on-disc machine. The MPS-SiCp with $1 \% \mathrm{Mg}$ addition in composite showed the possibility to tailor its properties to meet the engineering requirements by suitable choice of particle size variations. The study reveals that the MPS-SiC $\mathrm{p}_{\mathrm{p}}$ with $\mathrm{Mg}$ addition enhanced the wear resistance and hardness properties as compared to SPS when mixed in a definite proportion. The multiple particle sizes (AMC IV) exhibited better performance than the single particle size in terms of wear resistance due to the load bearing properties whereby $\mathrm{Mg}$ played a very important role as a wetting agent for interfacial bonding in the interfacial zone of matrix and reinforcement. Among the single particle size of silicon carbide, coarse size (AMC III) also showed better performance in wear resistance compared to the fine size of silicon carbide reinforced aluminium composite than other small sizes in the presence of $\mathrm{Mg}$.

\section{ACKNOWLEDGEMENTS}

The authors acknowledge the financial support by the Ministry of Education and IIUM to conduct this research work under Project No: PRGS 12-002-0002.

\section{REFERENCES}

[1] Singh J, Chauhan A. Overview of aluminium matrix composites for automotive applications. International Journal of Applied Engineering Research. 2014;9:95966.

[2] Fatchurrohman N, Sulaiman S, Sapuan SM, Ariffin MKA, Baharuddin BTHT. Analysis of a metal matrix composites automotive component. International Journal of Automotive and Mechanical Engineering. 2015;11:2531-40.

[3] Asif Iqbal AKM, Arai Y. Study on low-cycle fatigue behavior of cast hybrid metal matrix composites. International Journal of Automotive and Mechanical Engineering. 2015;11:2504-14.

[4] Bozic D, Dimcic B, Dimcic O, Stasic J, Rajkovic V. Influence of SiC particles distribution on mechanical properties and fracture of DRA alloys. Materials \& Design. 2010;31:134-41.

[5] Maleque M, Adebisi AA, Shah QH. Energy and cost analysis of weight reduction using composite brake rotor. International Journal of Vehicle Structures \& Systems. 2012;4:69-73.

[6] Stojanović B, Ivanović L. Application of aluminium hybrid composites in automotive industry. Technical Gazette. 2015;22:247-51.

[7] Adebisi AA, Maleque M, Rahman M. Metal matrix composite brake rotor: historical development and product life cycle analysis. International Journal of Automotive and Mechanical Engineering. 2011;4:471-80.

[8] Mohamad M, Marzuki HFA, Bakar SNA, Abdullah AN, Ubaidillah EAE, Abidin MFZ, et al. Effect of anodizing electrolyte for structural adhesives bonding study of aluminium-carbon laminates composites. International Journal of Automotive and Mechanical Engineering. 2014;10:2091-101.

[9] Abu Bakar MH, Raja Abdullah RI, Md. Ali MA, Kasim MS, Sulaiman MA, Ahmad SSN, et al. Surface Integrity of $\operatorname{lm} 6$ aluminum metal matrix composite 
when machined with high speed steel and uncoated carbide cutting tools. Journal of Mechanical Engineering and Sciences. 2014;6:854-62.

[10] Khan MAR, Rahman M, Kadirgama K, Maleque M, Ishak M. Prediction of surface roughness of Ti-6Al-4V in electrical discharge machining: A regression model. Journal of Mechanical Engineering and Sciences. 2011;1:16-24.

[11] Bhandare RG, Sonawane PM. Preparation of aluminium matrix composite by using stir casting method. International Journal of Engineering Advanced Technology. 2013;3:61-5.

[12] Ding Z, Fan Y, Qi H, Ren D, Guo J. Study on the SiC_p./Al-Alloy composite automotive brake rotors. Acta Metallurgica Sinica (English Letters). 2009;13:97480.

[13] Mishra AK, Sheokand R, Srivastava R. Tribological behaviour of Al 6061/SiC metal matrix composite by Taguchi's Techniques. International Journal of Scientific and Research Publications. 2012;2(10):1-8.

[14] Taufik RS, Adibah M NF, Muhamad MR, Hasib H. Feasibility study of natural fiber composite material for engineering application. Journal of Mechanical Engineering and Sciences. 2014;6:940-8.

[15] Huang SJ, Jeng YR, Semenov V, Dai YZ. Particle size effects of silicon carbide on wear behavior of SiCp-reinforced magnesium matrix composites. Tribology Letters. 2011;42:79-87.

[16] Bindumadhavan P, Wah HK, Prabhakar O. Dual particle size (DPS) composites: effect on wear and mechanical properties of particulate metal matrix composites. Wear. 2001;248:112-20.

[17] Maleque MA, Ghazal BA, Ali MY, Hayyan M, Ahmed AS. Wear behaviour of TiC coated AISI 4340 steel produced by TIG surface melting. Materials Science Forum: Trans Tech Publ; 2015. p. 76-80.

[18] Maleque M, Sugrib S. The tribological behaviour of Fe-C-Al cast iron-effect of temperature. Industrial Lubrication and Tribology. 2013;65:320-7.

[19] Bakar MHA, Abdullah RIR, Ali MAM, Kasim MS, Sulaiman MA, Ahmad SSN, et al. Surface integrity of LM6 aluminum metal matrix composite when machined with high speed steel and uncoated carbide cutting tools. Journal of Mechanical Engineering and Sciences. 2014;6: 854-62. 